\title{
Successful Endoscopic Management of Subacute Intestinal Obstruction Presenting 3 Years After Lodgement of a Coin in the Duodenal Cap
}

Individuals who ingest coins are usually simply observed, because the majority of coins which pass into the stomach move unimpeded through the gastrointestinal tract $[1,2]$. It is rare for ingested coins which pass through the pylorus to lodge in the small bowel, and even rarer for this not to present acutely but rather several years later. A 52-year-old man presented with a 9-month history of intermittent epigastric pain and profuse vomiting, each bout lasting a few hours. These episodes settled spontaneously, and he was entirely well in between. The patient had accidentally swallowed a coin over 3 years previously which had not obviously passed. Physical examination showed normal findings. An abdominal plain film showed a coin-shaped metallic density in his mid-abdomen. Gastroscopy revealed an Irish 50 pence coin in the duodenal cap (Figure $\mathbf{1}$ ). The coin was firmly adherent to the duodenal mucosa on one of its edges, but appeared to swing about this axis and intermittently occlude the pyloric opening. There was a duodenal diverticulum just proximal to the site of the coin. The coin was dislodged with a snare and

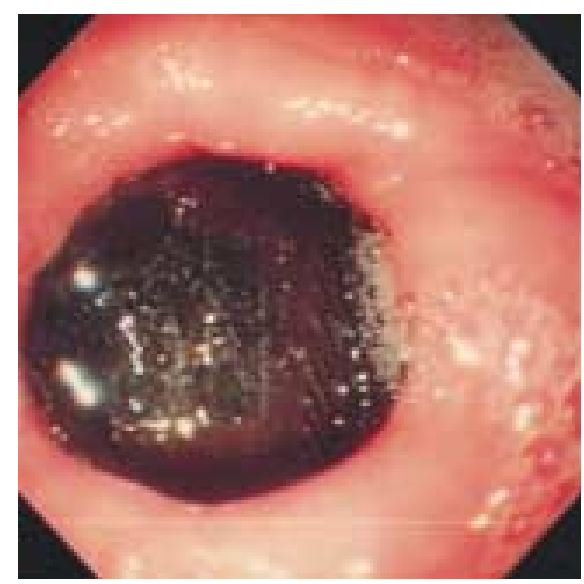

Figure 1 Endoscopic image of coin acting like a "ball-valve" at the pylorus. The coin was adherent to the mucosa in the duodenal cap by one of its edges, about which it appeared to swing retrieved using a basket (Figure 2 ). At follow up 3 months later, the patient remained well with no further gastrointestinal symptoms.

There are very few reports of patients ingesting foreign objects and presenting with subacute obstruction at a later date. One describes a patient in a persistent vegetative state who presented with obstruction 6 months after ingestion of the pulp of his feeding catheter [3], and another describes subacute small bowel obstruction in a patient with entrapped coins in an intraluminal duodenal diverticulum 20 years after ingestion [4]. Although rare, duodenal anomalies should be considered in the differential diagnosis of foreign bodies lodged in the duodenum [4]. Our patient had a duodenal diverticulum. Deformity around diverticula may promote lodgement of foreign objects.

\section{F. Byrne, G. McVey, K. Abdulla, S. Patchett}

Department of Gastroenterology, Beaumont Hospital, Dublin, Ireland

\section{References}

${ }^{1}$ Selivanov V, Sheldon GF, Cello JP et al. Management of foreign body ingestion. Ann Surg 1984; 199: 187-191

2 Stack LB, Munter DW. Foreign bodies in the gastrointestinal tract. Emerg Med Clin N Am 1996; 14: 493 - 521

${ }^{3}$ Tibbitts GM, Sorrell RJ. Duodenal obstruction from a gastric feeding tube. $\mathrm{N}$ Engl J Med 1999; 340: 970-971

${ }^{4}$ Adams DB. Endoscopic removal of entrapped coins from an intraluminal duodenal diverticulum 20 years after ingestion. Gastrointest Endosc 1986; 32: $415-416$

\section{Corresponding Author}

\section{F. Byrne, M.D.}

Duke University Medical Center Box 3189, Durham, NC 27710

USA

Fax: + 1-919-684-4695

E-mail: byrne006@mc.duke.edu

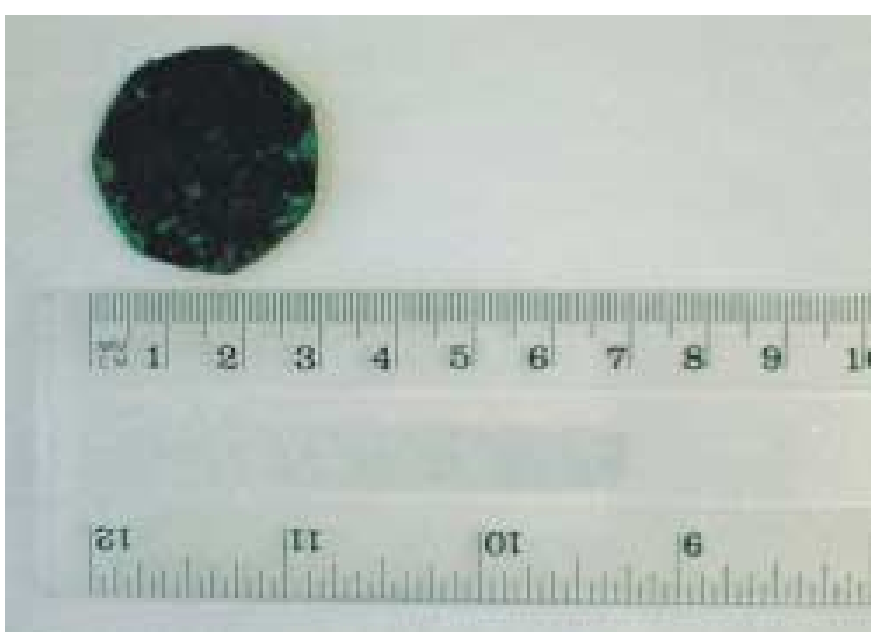

Figure 2 The retrieved Irish 50 pence coin was oxidised, and the date was obliterated. It measured about $28 \mathrm{~mm}$ in maximum diameter 